(C) 2022, The Authors. Published by Elsevier Inc. and Fass Inc. on behalf of the American Dairy Science Association ${ }^{\circledR}$. This is an open access article under the CC BY license (http://creativecommons.org/licenses/by/4.0/).

\title{
Pilot-scale production of exopolysaccharide from Leuconostoc pseudomesenteroides XG5 and its application in set yogurt
}

\author{
Lei Pan, ${ }^{1} \odot$ Qi Wang, ${ }^{1} \odot$ Liangfan Qu, ${ }^{2} \odot$ Lu Liang, ${ }^{1} \odot$ Ye Han, ${ }^{1} \odot$ Xianghe Wang, ${ }^{2,3 *} \odot$ and Zhijiang Zhou ${ }^{1 *} \odot$ \\ ${ }^{1}$ School of Chemical Engineering and Technology, Tianjin University, Tianjin 300350, China \\ ${ }^{2}$ Tianjin Research Institute of Industrial Microbiology Co., Ltd., Tianjin 300462, China \\ ${ }^{3}$ Tianjin SF-Bio Industrial Bio-Tec Co., Ltd., Tianjin 300462, China
}

\begin{abstract}
Exopolysaccharide from Leuconostoc pseudomesenteroides XG5 (XG5 EPS) is a linear dextran that is built by glucose units via $\alpha-1,6$ glycosidic bond. The primary objective of this study was to investigate the yield of XG5 EPS and its application in set yogurt. In laboratory scale, the culture conditions of XG5 EPS production were optimized using the L9 $\left(3^{3}\right)$ orthogonal test. Here, the optimized yield of XG5 EPS was 26.02 $\mathrm{g} / \mathrm{L}$ under the conditions of $100 \mathrm{~g} / \mathrm{L}$ sucrose, initial $\mathrm{pH}$ $7.0,25^{\circ} \mathrm{C}$ incubation, and $100 \mathrm{rpm}$ for $36 \mathrm{~h}$ in a shaking flask. Based on the optimized parameters of laboratory scale, a pilot fed-batch fermentation was performed in a 50-L bioreactor with an adjusted agitation speed of $20 \mathrm{rpm}$. The XG5 EPS yield reached $40.07 \mathrm{~g} / \mathrm{L}$ in fedbatch fermentation, which was $54 \%$ higher than that achieved in laboratory scale. In addition, XG5 EPS was added into set yogurt to investigate its effect on the stability of set yogurt. Our data demonstrated that the XG5 EPS improved the water-holding capacity, texture profile, and viscosity of set yogurt during cold storage compared with the controls. In particular, addition of $0.5 \%$ XG5 EPS increased the structure of 3-dimensional network of set yogurt, which eventually improved the physical stability of the set yogurt. Overall, this study provided new insights for exploring the pilot scale production and application of dextran.

Key words: Leuconostoc pseudomesenteroides XG5, exopolysaccharide, dextran, fed-batch fermentation, set yogurt
\end{abstract}

\section{INTRODUCTION}

Leuconostoc pseudomesenteroides XG5 is grampositive bacteria that is isolated from homemade wine.

Received July 13, 2021.

Accepted October 17, 2021

*Corresponding authors: wxianghe@126.com and zzj@tju.edu.cn
There is ample indication that L. pseudomesenteroides is the most common lactic acid bacteria in naturally fermented fruits and vegetables (Fessard and Remize, 2019). Lactic acid bacteria have been closely associated with humans, and some of them are classified as generally recognized as safe microorganisms. It has been demonstrated that L. pseudomesenteroides P1 exhibited antibacterial activities and probiotic potential, and the safety of $L$. pseudomesenteroides $\mathrm{P} 1$ were assessed in vivo and in vitro (Wang et al., 2018). Some studies have shown that L. pseudomesenteroides exhibit an anti-obesity function in obese mice with high-fat diets (Sun et al., 2020). Moreover, L. pseudomesenteroides is also considered to be an important producer of microbial exopolysaccharide (Xu et al., 2018; Farinazzo et al., 2020).

Microbial exopolysaccharide is an important and abundant compound that can be secreted by bacteria, fungi, and algae. Generally, microbial exopolysaccharide is divided into 2 groups: homopolysaccharide and heteropolysaccharide. Homopolysaccharide contains only one type of monosaccharide (e.g., dextran), whereas heteropolysaccharide consists of several monosaccharides (e.g., xanthan; Barcelos et al., 2020). In recent decades, microbial exopolysaccharide has gained attention of the food industry because it played an important role in fermented dairy product and bakery product, and it has the advantages of a low cost and short cycle (Freitas et al., 2017; Lynch et al., 2018). Meanwhile, microbial exopolysaccharide has great potential for applications, based on its chemical structure and biological activities. It has been reported that Lactobacillus plantarum RJF4 exopolysaccharide exerted antiproliferative effects on MiaPaCa2-pancreatic cancer cell line in an in vitro study (Dilna et al., 2015). Zhou et al. (2019) found that exopolysaccharide from Lactobacillus plantarum NCU116 modulated colonic mucosal homeostasis. We recently reported the chemical structures and functional properties of the exopolysaccharide from L. pseudomesenteroides XG5 (XG5 EPS, a linear dextran) (Zhou et al., 2018; Pan et al., 2020). 
Dextran is an important exopolysaccharide produced by bacteria, and it is a good choice for drug carriers, which can effectively control drug release (Chen et al., 2020). At present, the production of dextran generally includes conventional fermentation and dextransucrase biosynthesis (Yang et al., 2015; Vuillemin et al., 2018). It has been reported that the industry still employs the conventional fermentation to producet the commercial dextran, which may be due to the high cost and technical difficulty of dextran biosynthesis by dextransucrase (Li et al., 2020b). Until now, most studies have focused on the optimization of dextran production at the shake flask level (Kanimozhi et al., 2017; Xing et al., 2018). To the best of our knowledge, studies on the preparation of dextran in pilot scale were still rare. Considering the sustainable and cost strategy of optimizing XG5 EPS in pilot scale, the present work first employed orthogonal experimental design to optimize the yield of XG5 EPS in laboratory scale. Then, the XG5 EPS production was verified by batch fermentation in a $50-\mathrm{L}$ bioreactor containing a 35-L working volume, and the fed-batch fermentation was used to further increase the production of XG5 EPS. In this study, the beneficial parameters were obtained by XG5 EPS pilot production, which provides theoretical basis for industrial dextran production in the future. Moreover, antioxidant activity and application in set yogurt of XG5 EPS were investigated to further explore the applications of XG5 EPS in food industry.

\section{MATERIALS AND METHODS}

\section{XG5 EPS Extraction}

Leuconostoc pseudomesenteroides XG5 was isolated from homemade wine, and the stock culture of L. pseudomesenteroides XG5 was cultured in de Man, Rogosa, and Sharpe (MRS) broth with $20 \%$ (vol/vol) glycerol for long time preservation. The XG5 EPS was extracted by the method of Zhou et al. (2018). Briefly, L. pseudomesenteroides XG5 was grown in MRS medium supplemented with $12.5 \%$ (wt/vol) sucrose (MRS-S) at $30^{\circ} \mathrm{C}$ for $48 \mathrm{~h}$ unless otherwise specified. After that, the medium was boiled in a water bath at $100^{\circ} \mathrm{C}$ for
$15 \mathrm{~min}$ and centrifuged at $10,000 \times g$ for $30 \mathrm{~min}$ at $4^{\circ} \mathrm{C}$. Three volumes of cold ethanol $(95 \%, \mathrm{vol} / \mathrm{vol})$ were added to the supernatant and incubated overnight at $4^{\circ} \mathrm{C}$ to precipitate XG5 EPS. The precipitate was dissolved in deionized water, and trichloroacetic acid $(10 \%, \mathrm{wt} / \mathrm{vol})$ was added to the EPS solution to remove the proteins at $4^{\circ} \mathrm{C}$ for $12 \mathrm{~h}$. Finally, 3 volumes of cold ethanol $(95 \%, \mathrm{vol} / \mathrm{vol})$ were added to the supernatant and incubated overnight at $4^{\circ} \mathrm{C}$ to precipitate XG5 EPS. The precipitate was lyophilized for the further study.

\section{Optimization of Culture Conditions}

Leuconostoc pseudomesenteroides XG5 was activated by transfer to MRS broth medium and cultivated at $30^{\circ} \mathrm{C}$ for $24 \mathrm{~h}$ in $5 \mathrm{~mL}$ of MRS broth. First, the culture conditions of exopolysaccharide from $L$. pseudomesenteroides XG5 was investigated by the one-factor-at-atime method. Leuconostoc pseudomesenteroides XG5 $(2 \%, \mathrm{vol} / \mathrm{vol})$ was cultured in $50-\mathrm{mL}$ flasks with $15 \mathrm{~mL}$ of MRS-S; the MRS-S medium contains (per L) $5.5 \mathrm{~g}$ of glucose $\cdot \mathrm{H}_{2} \mathrm{O}, 125 \mathrm{~g}$ of sucrose, $10 \mathrm{~g}$ of tryptone, $10 \mathrm{~g}$ of beef extract powder, $5 \mathrm{~g}$ of yeast extract powder, 2.62 $\mathrm{g}$ of $\mathrm{K}_{2} \mathrm{HPO}_{4} \cdot 3 \mathrm{H}_{2} \mathrm{O}, 5 \mathrm{~g}$ of sodium acetate anhydrous, 2 $\mathrm{g}$ of ammonium citrate tribasic, $0.58 \mathrm{~g}$ of $\mathrm{MgSO}_{4} \cdot 7 \mathrm{H}_{2} \mathrm{O}$, $0.25 \mathrm{~g}$ of $\mathrm{MnSO}_{4} \cdot \mathrm{H}_{2} \mathrm{O}$, and $1 \mathrm{~mL}$ of Tween 80 , and was incubated at $30^{\circ} \mathrm{C}$ for $48 \mathrm{~h}$. In this work, the initial $\mathrm{pH}$ (5.0, 6.0, 7.0, 8.0, and 9.0), fermentation temperature $\left(25,30\right.$, and $\left.37^{\circ} \mathrm{C}\right)$, rotary speed $(0,50,100,150$, and $200 \mathrm{rpm})$, fermentation time $(12,24,36,48$, and $60 \mathrm{~h})$, and sucrose concentration (50,75, 100, 125, and 150 $\mathrm{g} / \mathrm{L})$ were optimized to improve the production of exopolysaccharide. Finally, L9 $\left(3^{3}\right)$ orthogonal test (Table 1) was applied to optimize the culture conditions, including initial $\mathrm{pH}$, fermentation temperature, and fermentation time. The biomass of L. pseudomesenteroides XG5 was measured at $600 \mathrm{~nm}$ by spectrophotometer (V-1600, MAPADA).

\section{Fed-Batch Fermentations}

Based on the optimized parameters of the $50-\mathrm{mL}$ flasks with a $15-\mathrm{mL}$ working volume, the working vol-

Table 1. Factors and levels for orthogonal test to optimize the culture conditions for production of exopolysaccharide from Leuconostoc pseudomesenteroides XG5

\begin{tabular}{llccc}
\hline & & \multicolumn{3}{c}{ Level } \\
\cline { 3 - 5 } Factor & Item & 1 & 2 & 3 \\
\hline $\mathrm{X}_{1}$ & Initial $\mathrm{pH}$ & 6.0 & 7.0 & 8.0 \\
$\mathrm{X}_{2}$ & Fermentation temperature $\left({ }^{\circ} \mathrm{C}\right)$ & 25 & 30 & 37 \\
$\mathrm{X}_{3}$ & Fermentation time $(\mathrm{h})$ & 24 & 36 & 48 \\
\hline
\end{tabular}


ume of fed-batch fermentation was upscaled to $35 \mathrm{~L}$. First, L. pseudomesenteroides XG5 was activated by transfer to MRS broth medium and cultivated at $30^{\circ} \mathrm{C}$ for $24 \mathrm{~h}$ in $700 \mathrm{~mL}$ of MRS broth, and the fermentation process was cultivated in the 50-L bioreactor (Yixing Pharmaceutical Equipment Factory) containing 2\% (vol/vol) inoculum. The parameters of bioreactor were set according to the following: fermentation temperature $25^{\circ} \mathrm{C}$, agitation speed $20 \mathrm{rpm}$, and fermentation time $60 \mathrm{~h}$. The fermentation medium contains (per L) $5.5 \mathrm{~g}$ of glucose $\cdot \mathrm{H}_{2} \mathrm{O}, 100 \mathrm{~g}$ of sucrose, $10 \mathrm{~g}$ of tryptone, $10 \mathrm{~g}$ of beef extract powder, $5 \mathrm{~g}$ of yeast extract powder, $2.62 \mathrm{~g}$ of $\mathrm{K}_{2} \mathrm{HPO}_{4} \cdot 3 \mathrm{H}_{2} \mathrm{O}, 5 \mathrm{~g}$ of sodium acetate anhydrous, $2 \mathrm{~g}$ of ammonium citrate tribasic, $0.58 \mathrm{~g}$ of $\mathrm{MgSO}_{4} \cdot 7 \mathrm{H}_{2} \mathrm{O}, 0.25 \mathrm{~g}$ of $\mathrm{MnSO}_{4} \cdot \mathrm{H}_{2} \mathrm{O}$, and $1 \mathrm{~mL}$ of Tween 80, with the initial $\mathrm{pH}$ value of 7.0. Notably, the $\mathrm{pH}$ of fermentation broth was adjusted to 6.5 during each fed-batch fermentation. Here, the fermentation broth was periodically sampled to determine dry cell weight, residual sucrose, glucose and fructose concentration, and XG5 EPS production.

\section{Antioxidant Activity In Vitro}

2,2-Diphenyl-1-Picrylhydrazyl Radical Scavenging Activity. The 2,2-diphenyl-1-picrylhydrazyl (DPPH) radical scavenging activity of XG5 EPS was determined according to Bomfim et al. (2020) with minor modifications. In brief, the XG5 EPS solution $(0.5 \mathrm{~mL}, 0.2-1.0 \mathrm{mg} / \mathrm{mL})$ was mixed with the $\mathrm{DPPH}$ (1 $\mathrm{mL}, 0.05 \mathrm{~m} M$, dissolved in ethanol). Subsequently, the mixture was shaken and incubated at $25^{\circ} \mathrm{C}$ for 30 min in the dark, and centrifuged at 5,000 $\times g$ for 5 min at $25^{\circ} \mathrm{C}$. Absorbance of the supernatant was measured at $517 \mathrm{~nm}$ by spectrophotometer (V-1600, MAPADA), ascorbic acid (Vc) was used as the positive control. The DPPH radical scavenging activity was calculated as

Scavenging activity $(\%)=\left[1-\left(\mathrm{A}_{2}-\mathrm{A}_{1}\right) / \mathrm{A}_{0}\right] \times 100$,

where $A_{0}$ represents the absorbance of the control (DPPH and water), $\mathrm{A}_{1}$ represents the absorbance of the blank (XG5 EPS and ethanol), and $\mathrm{A}_{2}$ represents the absorbance of the sample (XG5 EPS and DPPH).

2,2'-Azino-bis(3-Ethylbenzothiazoline-6-Sulfonic Acid) Radical Scavenging Activity. The 2,2'-azino-bis(3-ethylbenzothiazoline-6-sulfonic acid) (ABTS) radical scavenging activity of XG5 EPS was conducted according to Liu et al. (2016) with modifications. Briefly, the ABTS radical was produced by reacting ABTS solution ( $7 \mathrm{~m} M$, dissolved in water) with potassium persulfate (final concentration 2.45 $\mathrm{m} M$ ) at room temperature for $16 \mathrm{~h}$ in the dark. The stock solution of ABTS radical was diluted with ethanol to an absorbance of $0.70 \pm 0.02$ at $734 \mathrm{~nm}$ and stocked before use. Then, the XG5 EPS solution $(50 \mu \mathrm{L}, 0.2-1.0$ $\mathrm{mg} / \mathrm{mL}$ ) was mixed with $1 \mathrm{~mL}$ of the ABTS diluent. Moreover, the mixture was shaken and incubated at $25^{\circ} \mathrm{C}$ for $6 \mathrm{~min}$ in the dark, and centrifuged at 5,000 $\times g$ for 5 min. Absorbance of the supernatant was measured at $734 \mathrm{~nm}$ by spectrophotometer (V-1600, MAPADA), and Vc was used as the positive control. The ABTS radical scavenging activity was calculated as

\section{Scavenging activity $(\%)=\left[1-\left(\mathrm{A}_{2}-\mathrm{A}_{1}\right) / \mathrm{A}_{0}\right] \times 100$,}

where $\mathrm{A}_{0}$ represents the absorbance of the control (ABTS and water), $A_{1}$ represents the absorbance of the blank (XG5 EPS and ethanol), and $\mathrm{A}_{2}$ represents the absorbance of the sample (XG5 EPS and ABTS).

Ferrous Ion Chelating Ability. Ferrous ion chelating ability was evaluated as previously described ( $\mathrm{Li}$ et al., 2020a). In brief, the reaction system contained XG5 EPS solution $(0.5 \mathrm{~mL}, 0.2-1.0 \mathrm{mg} / \mathrm{mL})$, ferroizine $(0.15 \mathrm{~mL}, 5 \mathrm{mM}), \mathrm{FeCl}_{2}(0.1 \mathrm{~mL}, 2 \mathrm{mM})$, and $0.55 \mathrm{~mL}$ of methanol; the mixture was shaken and incubated at $25^{\circ} \mathrm{C}$ for $10 \mathrm{~min}$. Absorbance of the mixture was measured at $562 \mathrm{~nm}$ by spectrophotometer (V-1600, MAPADA), Ethylene diamine tetra acetic acid was used as the positive control. Ferrous ion chelating ability was calculated as

Ferrous ion chelating ability $(\%)=\left(1-\mathrm{A} / \mathrm{A}_{0}\right] \times 100$,

where $A_{0}$ represents the absorbance of the control (water instead of XG5 EPS) and A represents the absorbance of the sample (XG5 EPS).

Preparation of Set Yogurt. Commercial milk (100 $\mathrm{g}$ of milk contained $3.2 \mathrm{~g}$ of protein and $3.8 \mathrm{~g}$ of fat) was transferred into sterilized glass jars and heated to $70^{\circ} \mathrm{C}$. The sucrose $(7 \%, \mathrm{wt} / \mathrm{wt})$ was added into milk, the mixture was homogenized at $30 \mathrm{MPa}$ and subsequently heat treated at $95^{\circ} \mathrm{C}$ for $300 \mathrm{~s}$. Afterward, XG5 EPS were added to the mixture and mixed well, and then cooled down to $43^{\circ} \mathrm{C}$ to add the yogurt starter (YO-PROX 699, Bioprox). The final concentration of XG5 EPS was 0 (control), $0.1 \%$ (LXE), and $0.5 \%$ (HXE), respectively. Thereafter, the set yogurt sample was poured into $100-\mathrm{mL}$ plastic cups and incubated at $43^{\circ} \mathrm{C}$ until $\mathrm{pH}$ reached $4.5 \pm 0.1$. Last, the set yogurt was refrigerated at $4^{\circ} \mathrm{C}$ for 1,7 , and $14 \mathrm{~d}$.

Water-Holding Capacity. Water-holding capacity (WHC) of set yogurt was determined according to the method of Fu et al. (2018) with some modification. Briefly, $10 \mathrm{~g}$ of the set yogurt was centrifuged at 3,000 
$\times g$ for $30 \mathrm{~min}$. The WHC was evaluated using following equation:

$$
\mathrm{WHC}(\%)=\left(1-\mathrm{W}_{2} / \mathrm{W}_{1}\right) \times 100,
$$

where $\mathrm{W}_{1}$ is the weight of set yogurt before centrifugation $(g)$, and $\mathrm{W}_{2}$ is the weight of supernatant after centrifugation $(g)$. The WHC of set yogurt sample was evaluated 3 times during cold storage (1, 7, and $14 \mathrm{~d}$ ).

Texture Profile Analysis. Texture profile analysis of the set yogurt sample was assessed by a texture analyzer (TA-XT plus, Stable Micro Systems Ltd.) equipped with a $36-\mathrm{mm}(\mathrm{P} / 36 \mathrm{R})$ cylindrical probe. The set yogurt sample was tested at $1 \mathrm{~mm} / \mathrm{s}$. Trigger force was $5.0 \mathrm{~g}$ and the compression ratio was $30 \%$. The hardness, cohesiveness, chewiness, and resilience of set yogurt sample was collected and analyzed by the Texture Exponent 32 software (Stable Micro Systems, version 6.1.18.0). The texture profile of set yogurt sample was evaluated 3 times during cold storage (1, 7 , and $14 \mathrm{~d}$ ).

Sensory Evaluation. The sensory evaluation of set yogurt samples was assessed by the modified method of Hovjecki et al. (2021). Briefly, sensory evaluation was conducted by 6 panelists ( 3 women and 3 men), aged 25 to 50 , recruited from the laboratory. For all samples, odor was the first property assessed, and then the appearance, texture properties and consumer acceptance were evaluated, with the scores ranging from minimum (0) to maximum (10). The sensory evaluation of set yogurt sample was performed 3 times during cold storage $(1,7$, and $14 \mathrm{~d})$.

Rheological Analysis. Rheological testing was performed according to the previous method with modification (Zhao et al., 2020). In brief, rheological properties of set yogurt sample was analyzed by rheometer (Physica MCR301, Anton Paar Ltd.) with a measuring plate (PP50, 1.000-mm gap) at $4^{\circ} \mathrm{C}$. The oscillation strain results indicated that the value of $0.5 \%$ was suitable for all samples. Viscosity was measured at shear rate from $0.1 \mathrm{~s}^{-1}$ to $50 \mathrm{~s}^{-1}$. Three-interval thixotropy test was performed to obtain the antishear properties of set yogurts; the sample was oscillated at $1 \mathrm{~Hz}$ with $0.5 \%$ strain until steady state reached. Then high shear rate $\left(1,000 \mathrm{~s}^{-1}\right)$ was loaded in very short period $(1 \mathrm{~s})$ to induce the structure deformation. The storage modulus $\left(\mathbf{G}^{\prime}\right)$, loss modulus $\left(\mathbf{G}^{\prime \prime}\right)$, and loss tangent $(\tan \delta$, tan $\left.\delta=\mathrm{G}^{\prime \prime} / \mathrm{G}^{\prime}\right)$ were monitored until steady state recovered. The rheological testing of set yogurt sample was performed 3 times during cold storage (1, 7, and $14 \mathrm{~d}$ ).

Microstructure. Microstructure of set yogurt sample was observed by scanning electron microscopy (Regulus 8100, Hitachi) according to the previous method with modification (Khubber et al., 2021). In brief, the set yogurt sample was diluted (1:6) in deionized water and lyophilized. Afterward, the set yogurt samples were coated with a gold-palladium layer and scanned. The electron accelerating voltage was $3.0 \mathrm{kV}$ and the magnification was $5,000 \times$.

\section{Statistical Analysis}

Data are presented as mean \pm standard deviation in triplicate, and statistical analysis was performed using SPSS Statistics 28 (IBM Corp.). One-way ANOVA was used to determine the significant differences among the groups followed by Duncan's multiple comparison test.

\section{RESULTS AND DISCUSSION}

\section{Optimization of Culture Conditions for Improving Production of XG5 EPS}

The production of XG5 EPS was closely related to culture conditions (e.g., initial $\mathrm{pH}$, fermentation temperature, rotary speed, fermentation time, and substrate concentration), which may affect the growth of L. pseudomesenteroides XG5. The maximum level of XG5 EPS was observed at $\mathrm{pH} 7.0$ with $28.86 \pm$ $0.75 \mathrm{~g} / \mathrm{L}$ (Figure 1a). Previously, Xing et al. (2018) found that the optimal value of initial $\mathrm{pH}$ was 7.18 for exopolysaccharide production of Leuconostoc mesenteroides strain. The effect of fermentation temperature on XG5 EPS production is shown in Figure 1b. The XG5 EPS production reached the maximum of $31.05 \pm$ $0.72 \mathrm{~g} / \mathrm{L}$ at $25^{\circ} \mathrm{C}$, and rapidly decreased thereafter. The fermentation temperature may have an effect on the enzyme activities and further effect the production of XG5 EPS. The result was consistent with the optimal fermentation temperature of Leuconostoc mesenteroides KIBGE-IB22 (Siddiqui et al., 2014). Considering the cost-effectiveness, fermentation temperature lower than room temperature was not used in this study. As shown in Figure 1c, the production of XG5 EPS showed a steady increase (from 0 to $100 \mathrm{rpm}$ ). Remarkably, the production of XG5 EPS was decreased when the rotary speed was higher than $100 \mathrm{rpm}$. The result might be due that the high rotary speed increased shear stress and oxygen supply, which affected the production of XG5 EPS in the shake flask fermentation (Zhang et al., 2019). In addition, the production of XG5 EPS reached $32.69 \pm 0.93 \mathrm{~g} / \mathrm{L}$ until $36 \mathrm{~h}$ of fermentation, and then slightly decreased (Figure 1d). Similar to previous findings, the preferable fermentation time of levan from the Tanticharoenia sakaeratensis was 35 h (Aramsangtienchai et al., 2020). The production of 
Table 2. The L9 $\left(3^{3}\right)$ orthogonal test applied for optimizing production of Leuconostoc pseudomesenteroides XG5 exopolysaccharide (EPS)

\begin{tabular}{lcccc}
\hline \multicolumn{3}{c}{ Factor } & \\
\cline { 2 - 3 } No. & $\mathrm{X}_{1}(\mathrm{pH})$ & $\mathrm{X}_{2}\left({ }^{\circ} \mathrm{C}\right)$ & $\mathrm{X}_{3}(\mathrm{~h})$ & $(\mathrm{g} / \mathrm{L})$ \\
\hline 1 & 6.0 & 25 & 24 & 18.55 \\
2 & 6.0 & 30 & 36 & 19.67 \\
3 & 6.0 & 37 & 48 & 9.36 \\
4 & 7.0 & 25 & 36 & 26.02 \\
5 & 7.0 & 30 & 48 & 21.98 \\
6 & 7.0 & 37 & 24 & 13.26 \\
7 & 8.0 & 25 & 48 & 19.64 \\
8 & 8.0 & 30 & 24 & 18.10 \\
9 & 8.0 & 37 & 36 & 11.02 \\
$\mathrm{~K}_{1}$ & 47.57 & 64.21 & 49.90 & \\
$\mathrm{~K}_{2}$ & 61.26 & 59.74 & 56.71 & \\
$\mathrm{~K}_{3}$ & 48.76 & 33.64 & 50.98 & \\
$\mathrm{R}$ & 4.56 & 10.19 & 2.27 & \\
\hline
\end{tabular}

${ }^{1} \mathrm{~K}=$ sum of the experimental indices of this level in each factor; $\mathrm{R}=$ difference between the average of $K_{\max }$ and $K_{\min }$ values.

XG5 EPS might be influenced by the sucrose concentration. As shown in Figure 1e, the percent yield of XG5 EPS increased from $43.71 \pm 1.03 \%$ to $53.33 \pm$ $0.81 \%$ with increasing the sucrose concentration from
50 to $100 \mathrm{~g} / \mathrm{L}$, and the production of XG5 EPS was $26.67 \pm 0.41 \mathrm{~g} / \mathrm{L}$ in MRS-S medium containing 100 $\mathrm{g} / \mathrm{L}$ sucrose. Here, we integrated the results from the one-factor-at-a-time method, an orthogonal test was applied to optimize the culture conditions to further improve production of XG5 EPS. The optimal culture condition was obtained with the initial $\mathrm{pH} 7.0$ of MRS broth at $25^{\circ} \mathrm{C}$ for $36 \mathrm{~h}$, and the optimal yield of XG5 EPS reached $26.02 \pm 0.82 \mathrm{~g} / \mathrm{L}$ (Table 2). As shown in Table 3, initial $\mathrm{pH}$ and fermentation temperature had significant effects on the production of XG5 EPS. According to above-described results, the optimal culture conditions for XG5 EPS production were initial $\mathrm{pH}$ 7.0, fermentation temperature $25^{\circ} \mathrm{C}, 100 \mathrm{RPM}$, fermentation time $36 \mathrm{~h}$, and sucrose concentration $100 \mathrm{~g} / \mathrm{L}$ at the laboratory level.

\section{Fed-Batch Fermentation of XG5 EPS in 50 L Bioreactor}

To further explore the yield of XG5 EPS, the 50-L bioreactor was used to conduct batch fermentation. The

b

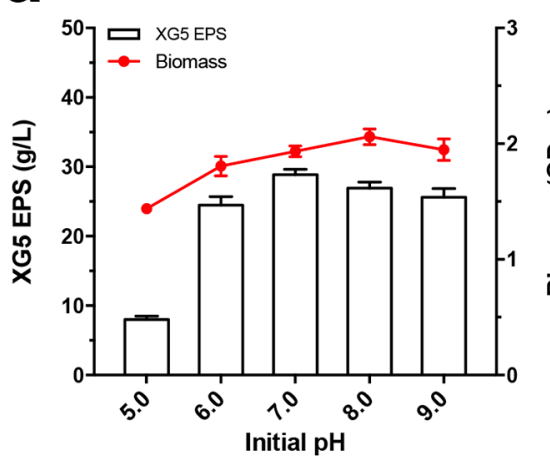

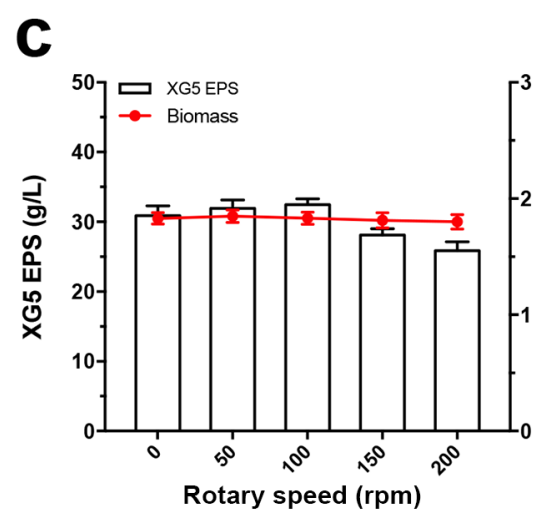

d

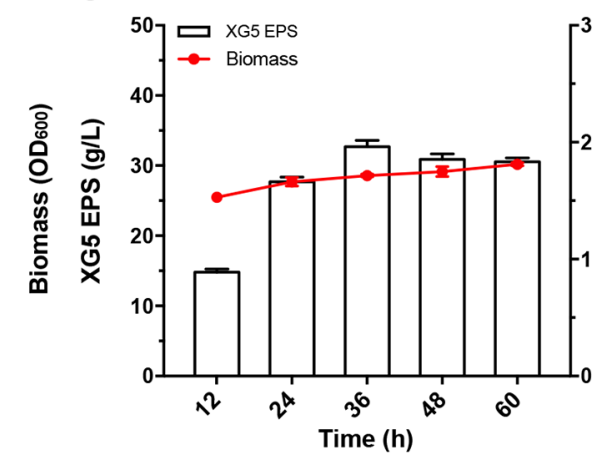

e

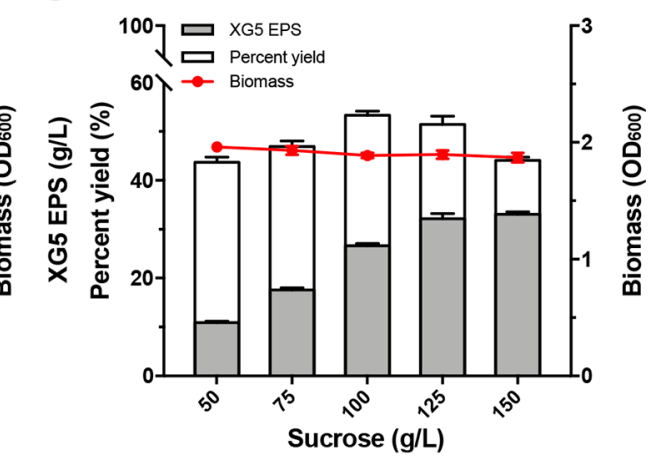

Figure 1. Optimization of culture conditions to enhance the production of exopolysaccharide from Leuconostoc pseudomesenteroides XG5 (XG5 EPS). The L. pseudomesenteroides XG5 was cultivated in de Man, Rogosa, and Sharpe medium supplemented with $12.5 \%$ (wt/vol) sucrose with different (a) initial pH, (b) fermentation temperature, (c) rotary speed, (d) fermentation time, and (e) sucrose concentration. Biomass was measured by optical density at $600 \mathrm{~nm}\left(\mathrm{OD}_{600}\right)$. Data are presented as mean $\pm \mathrm{SD}$ in triplicate. 
yield of XG5 EPS reached a maximum of $29.63 \mathrm{~g} / \mathrm{L}$ in $24 \mathrm{~h}$ of batch fermentation, and declined slightly thereafter (Figure 2a). The XG5 EPS decrease may be due to the use of XG5 EPS by L. pseudomesenteroides XG5 after $24 \mathrm{~h}$ of fermentation. Similarly, Abdeshahian et al. (2020) found that $\beta$-glucan accumulated in the initial $72 \mathrm{~h}$ of fermentation time and later consumed. It is remarkable that the higher dry cell weight was achieved in $24 \mathrm{~h}$ of batch fermentation, and the maximum yield of XG5 EPS was harvested at this time. In addition, we found that the glucose concentration of fermentation broth was slow to decrease during fermentation. The fructose content of fermentation broth increased to $13 \mathrm{~g} / \mathrm{L}$ at $24 \mathrm{~h}$ and then decreased; we speculate that fructose may be used by L. pseudomesenteroides XG5 for its own growth.

As shown in Figure 2b, sucrose concentration declined to $67 \mathrm{~g} / \mathrm{L}$ after $12 \mathrm{~h}$ of fermentation. To attain higher XG5 EPS production, sucrose was added once at $12 \mathrm{~h}$ during the fed-batch fermentation. Subsequently, the sucrose concentration increased to $103 \mathrm{~g} / \mathrm{L}$. Remarkably, the yield of XG5 EPS reached a maximum of $40.07 \mathrm{~g} / \mathrm{L}$ after $42 \mathrm{~h}$ of fermentation, which was $35.24 \%$ higher than that of batch fermentation. A previous study has shown that the yield of microbial polysaccharide enhanced $19.79 \%$ by fed-batch fermentation (Mummaleti et al., 2021). Indeed, the sucrose supplied at $18 \mathrm{~h}$ during the fed-batch fermentation, but the viscosity of the fermentation broth was too high, and the density of the fermentation broth was lower than that of sucrose at the $18 \mathrm{~h}$ of fermentation, which meant that the sucrose could not be mixed with the fermentation broth after feeding. Finally, the sucrose was fed at $12 \mathrm{~h}$ during the fed-batch fermentation. Currently, many researchers have attempted to extract the dextran by the fermentation of different bacteria, most of which have the relatively low yields of dextran. For instance, it was reported that L. pseudomesenteroides YF32 only yielded the $12.5 \mathrm{~g} / \mathrm{L}$ of dextran in MRS medium supplemented with sucrose (Yang et al., 2018). In addition, Castro-Rodriguez et al. (2019) found that the yield of dextran from L. mesenteroides SF3 was $20 \mathrm{~g} / \mathrm{L}$. Unfortunately, these studies on the yield of dextran were only at the laboratory level, and the pilot production of dextran have not been given enough at- tention, whereas the yield of dextran reached $40.07 \mathrm{~g} / \mathrm{L}$ in a 50-L bioreactor in our study. Therefore, this study provides a feasible strategy for industrial production of dextran.

\section{Antioxidant Activity of XG5 EPS In Vitro}

The DPPH and ABTS radical scavenging activity and ferrous ion chelating ability were used to evaluate the antioxidant activity of XG5 EPS. The antioxidant activity of XG5 EPS and ascorbic acid or EDTA are shown in Figure 3, the DPPH and ABTS radical scavenging activity of XG5 EPS at all concentrations were much lower than ascorbic acid (Figure 3a,b). Previously, similar results were observed that the highest DPPH radical scavenging activity of exopolysaccharide from Streptococcus thermophilus GST-6 and Enterococcus faecium WEFA23 were about 10\% (Zhang et al., 2016, Jia et al., 2019). As shown in Figure 3c, the ferrous ion chelating ability of XG5 EPS slightly increased with the rising of XG5 EPS concentration, and it reached to $7.63 \pm 1.61 \%$ at the concentration of $1.0 \mathrm{mg} / \mathrm{mL}$. It has been reported that the antioxidant activity of polysaccharides might be related to molecular weight, composition and glycosidic bonds (Li et al., 2019). Overall, the results showed that XG5 EPS might slightly have antioxidant activity in vitro.

\section{Water-Holding Capacity, Texture Profile Analysis, and Sensory Evaluation of Set Yogurt During Cold Storage}

Water-holding capacity was investigated to evaluate the stability of the set yogurt. As shown in Table 4, the WHC of set yogurt significantly increased after adding of XG5 EPS, especially in the HXE group. This phenomenon was probably caused by the fact that XG5 EPS bind water into the milk base, thereby improving the stability of set yogurt. Moreover, XG5 EPS reacts with the milk constituents, mainly the proteins, to increase the level of water hydration (Tamime and Robinson, 1999). There was evidence that the WHC of set yogurt significantly increased after addition of $\beta$-glucan (Zhao et al., 2020). Additionally, the change in $\mathrm{pH}$ values of yogurts during cold storage is shown in

Table 3. Significance analysis of the L9 $\left(3^{3}\right)$ orthogonal test

\begin{tabular}{lccrc}
\hline Factor $^{1}$ & Sum of deviation square & Mean of square & $F$-value & $P$-value \\
\hline $\mathrm{X}_{1}$ & 38.309 & 19.155 & 61.641 & 0.016 \\
$\mathrm{X}_{2}$ & 181.794 & 90.897 & 292.514 & 0.003 \\
$\mathrm{X}_{3}$ & 8.913 & 4.457 & 14.342 & 0.065 \\
Error & 0.621 & 0.311 & & \\
\hline
\end{tabular}

${ }^{1}$ See Table 1 for factors. 
a

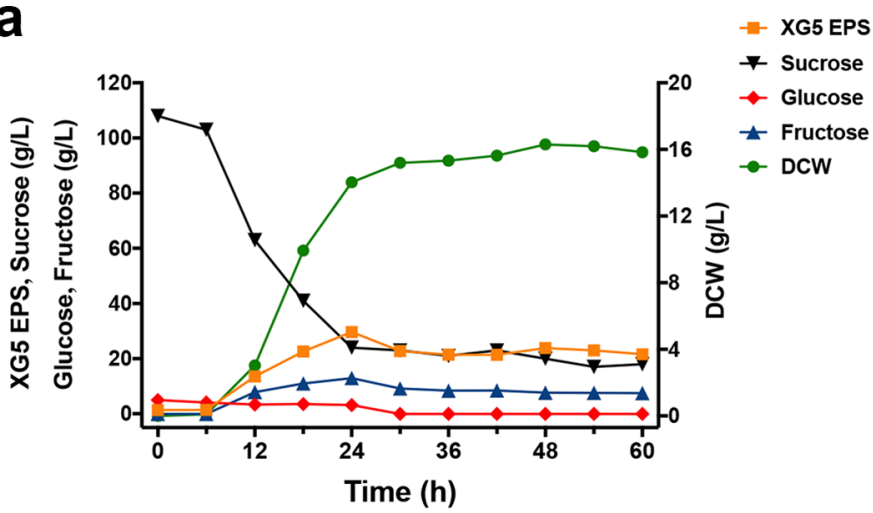

b

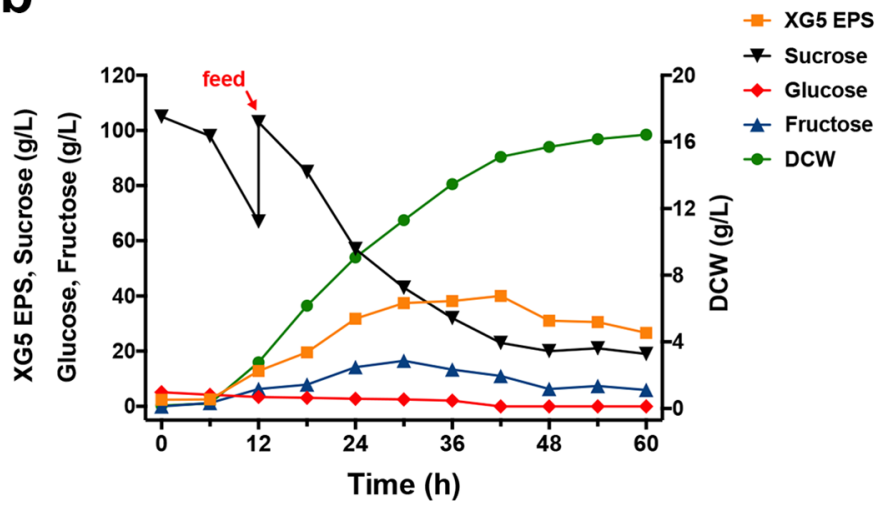

Figure 2. Fed-batch fermentation of Leuconostoc pseudomesenteroides XG5 for the production of XG5 exopolysaccharide (EPS). (a) Batch fermentation. (b) Sucrose was fed at $12 \mathrm{~h}$ during the fed-batch fermentation. ( $\mathbf{\square}$, XG5 EPS; $\mathbf{\nabla}$, sucrose; $\bullet$ glucose; $\mathbf{\Delta}$, dructose; $\bullet$ dry cell weight).

Table 4. Compared with control yogurts, the set yogurt containing $0.5 \%$ XG5 EPS showed significantly lower $\mathrm{pH}$ values. A similar result was also found in the previous study that low-methoxyl pectin added set yogurts showed lower $\mathrm{pH}$ compared with controls (Khubber et al., 2021).

Texture profile analysis of set yogurts containing different concentrations of XG5 EPS are shown in Table 4. The hardness (force 1) of set yogurt containing $0.5 \%$ XG5 EPS was remarkably lower than that of the controls during cold storage period of 7 and $14 \mathrm{~d}$. The lower hardness of set yogurt containing 0.5\% XG5 EPS could be attributed to its higher WHC (Table 4) and 3-dimensional network structure (Figure 5c, f, and i). Similar observations have been reported for set yogurt containing date palm spikelet extracts (Almusallam et al., 2021). The chewiness values indicated that the addition of $0.5 \%$ XG5 EPS resulted in set yogurts with considerably lower chewiness during cold storage period of 7 and $14 \mathrm{~d}$, which was similar to the previous study (Kaur and Riar, 2020). Remarkably, the resilience of set yogurt containing 0.5\% XG5 EPS expressed observ- a

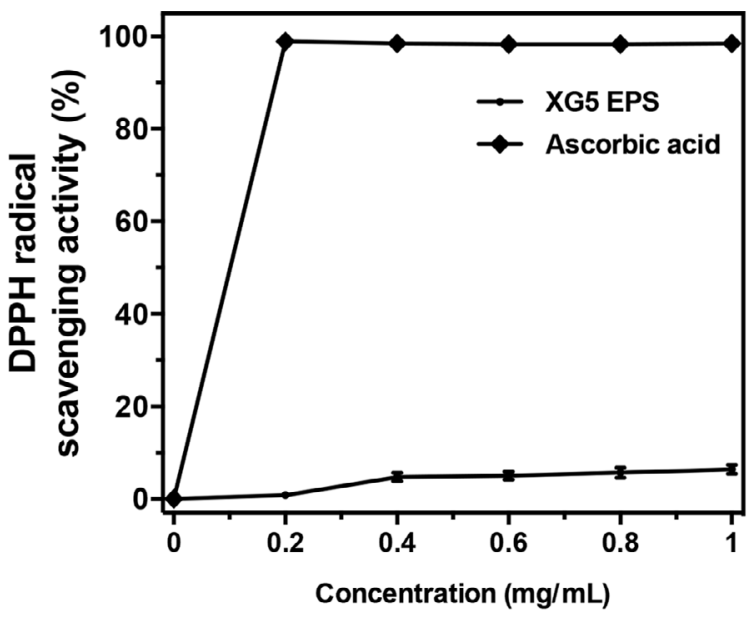

b

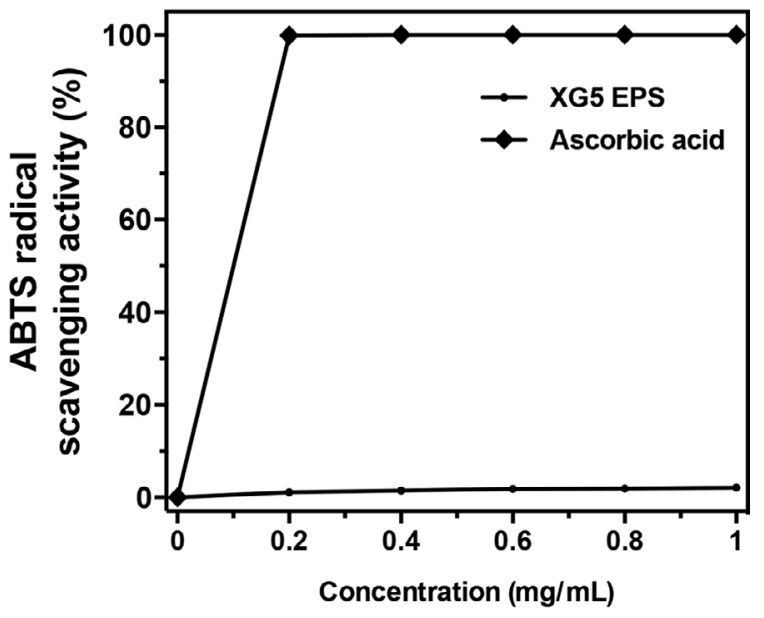

C

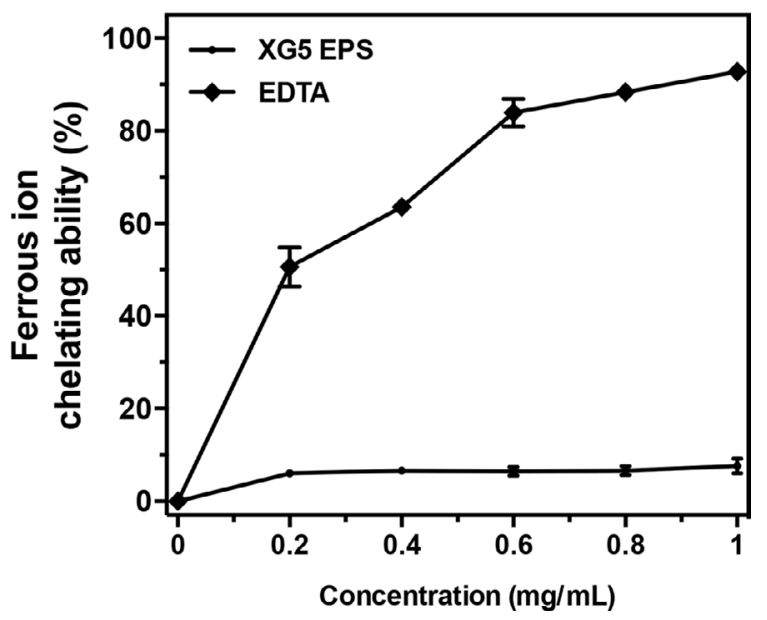

Figure 3. Antioxidant activity of Leuconostoc pseudomesenteroides XG5 exopolysaccharide (XG5 EPS) in vitro. (a) 2,2-Diphenyl1-picrylhydrazyl (DPPH) radical scavenging activity, (b) 2,2'-azinobis(3-ethylbenzothiazoline-6-sulfonic acid) (ABTS) radical scavenging activity, and (c) ferrous ion chelating ability. Data are presented as mean \pm SD in triplicate. 


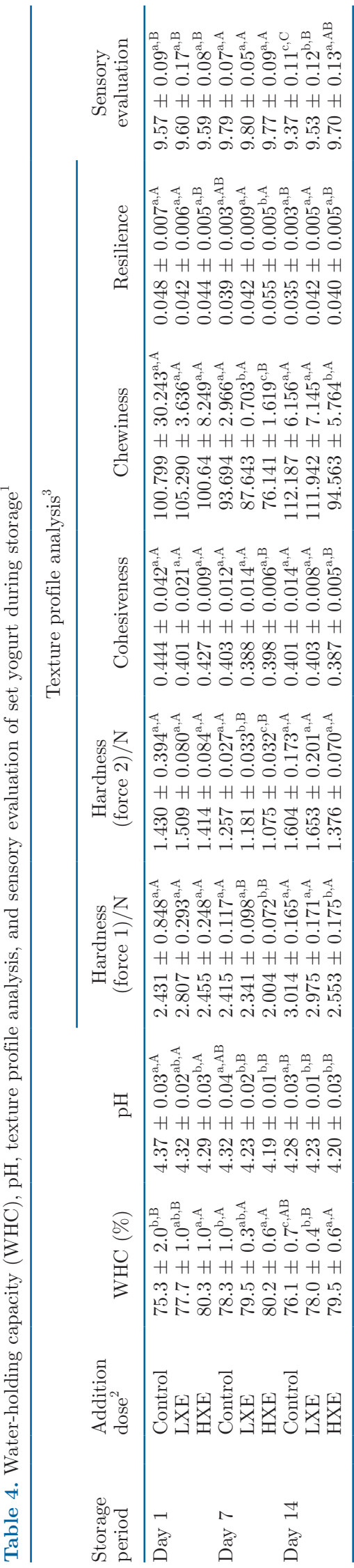

able improvement at the cold storage period of $7 \mathrm{~d}$ in comparison with the controls. Moreover, XG5 EPS enhanced the sensory evaluation of set yogurt with the cold storage period of $14 \mathrm{~d}$. The sensory results are related to WHC, which may be due to the observation of whey in the controls at the cold storage period of $14 \mathrm{~d}$.

\section{Rheological Properties of the Set Yogurt During Cold Storage}

The viscosity of set yogurts decreased with the increasing of shear rate, indicating that all the set yogurts exhibited shear-thinning behavior (Figure $4 \mathrm{a}, \mathrm{d}, \mathrm{g}$ ). It is remarkable that the viscosity of set yogurt added with $0.5 \%$ XG5 EPS is significantly higher than that of the control group at shear rate from 0.1 to $50 \mathrm{~s}^{-1}$. The possible explanation was that exopolysaccharide interact with casein micelles to form a strong network, which contributes to increase the viscosity of the set yogurt (Nguyen et al., 2017). According to $\mathrm{Xu}$ et al. (2019) the viscosity of set yogurt increased when okra polysaccharide was added to set yogurt. In addition, a 3-interval thixotropy test was performed to obtain the antishear ability of set yogurts during cold storage. Thixotropy results showed that transient shear stress changed the structure of all set yogurts. Meanwhile, the storage modulus $\left(\mathrm{G}^{\prime}\right)$ and loss modulus $\left(\mathrm{G}^{\prime \prime}\right)$ of set yogurt containing XG5 EPS were higher than that of the controls during cold storage period of 7 and $14 \mathrm{~d}$ (Figure $4 \mathrm{e}, \mathrm{h})$. The loss tangent $\left(\tan \delta, \tan \delta=\mathrm{G}^{\prime \prime} / \mathrm{G}^{\prime}\right.$ ) of all samples are shown in Figure $4 \mathrm{c}$, $\mathrm{f}$, and $\mathrm{i}$, it is useful to evaluate the solid or liquid behavior of set yogurts during loading a transient shear stress (Belsito et al., 2017). When $\tan \delta<1$, the sample exhibits a solids-like behavior, whereas $\tan \delta>1$ indicates that the sample has liquid-like behavior (Silva et al., 2016). In this study, all samples presented low values of tan $\delta$ than 1 , indicating that all set yogurts maintained a solids-like behavior. However, there was no difference in $\tan \delta$ values for all set yogurt samples during cold storage.

\section{Microstructure}

Microstructure difference among the set yogurt samples is shown in Figure 5, the structure of 3-dimensional network was observed in the set yogurt containing XG5 EPS during cold storage (Figure 5c, f and i), and the structure of 3-dimensional network improved when the concentration of XG5 EPS increased. In contrast, no similar structure was visualized in the set yogurt only containing sucrose. A previous study found that adding Salecan, a macromolecular glucan, to set yogurt formed an extra string-like structure, which strengthened the 

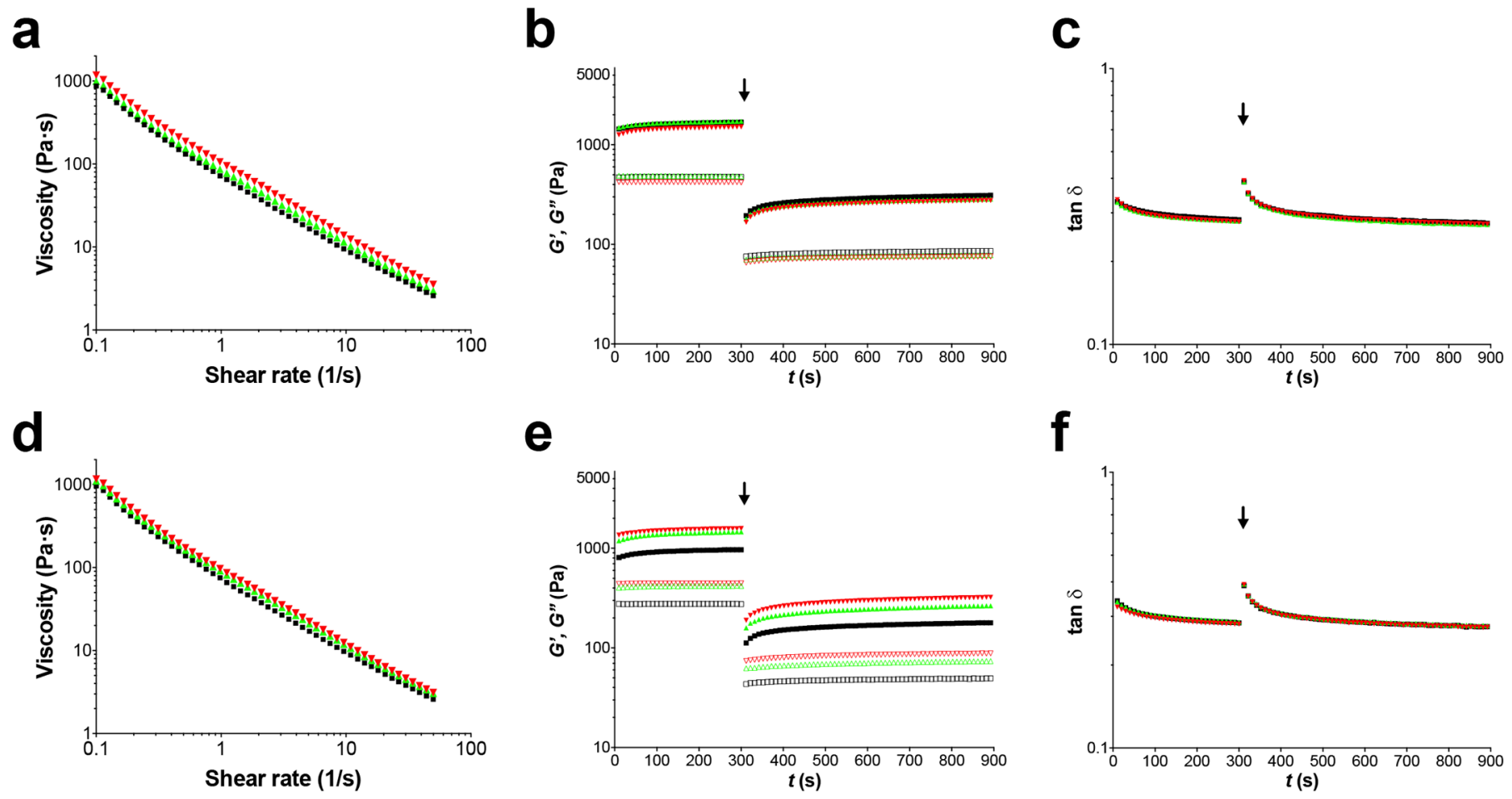

$\mathbf{e}$
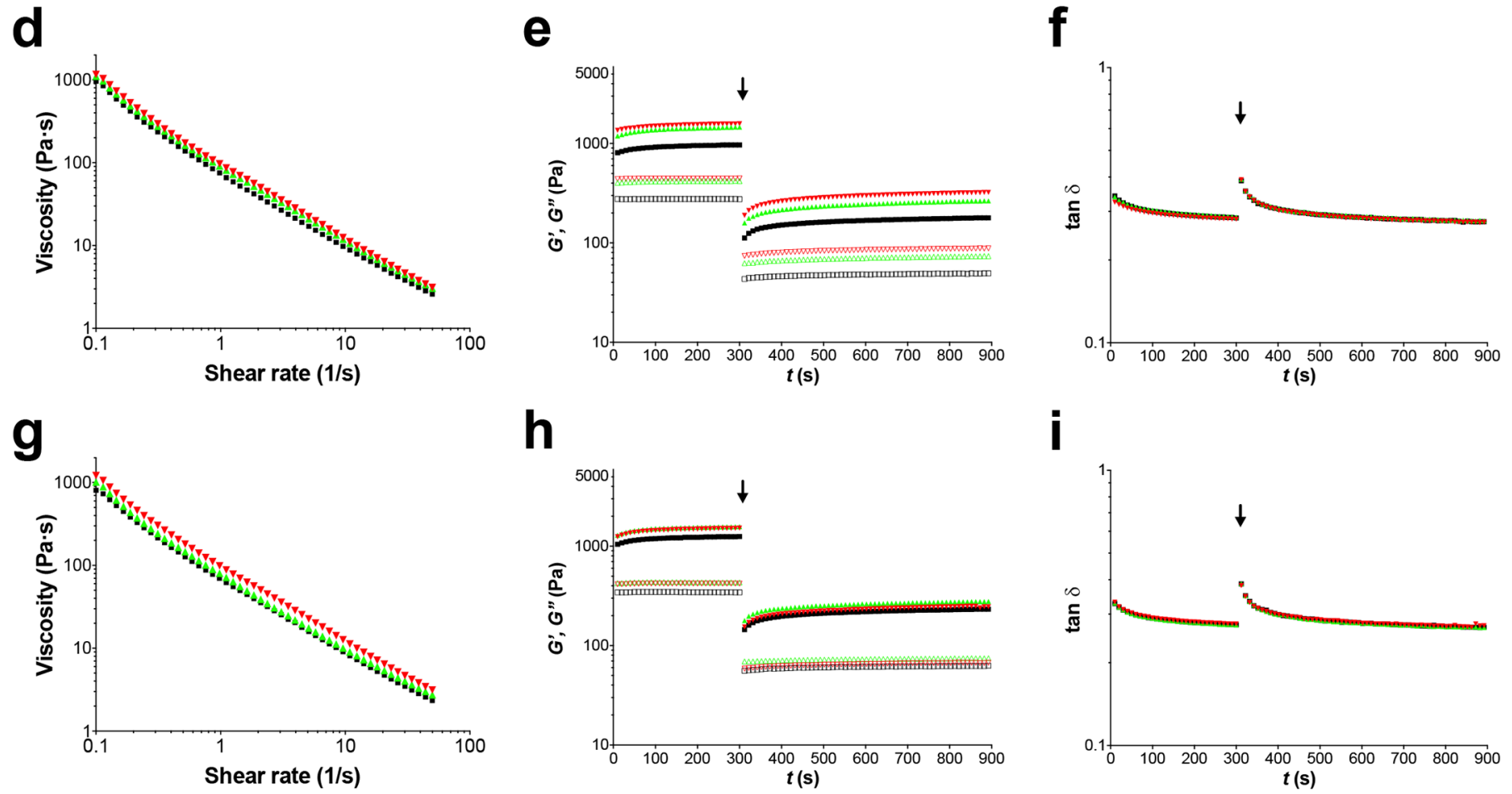

Figure 4. Rheological properties of set yogurts. Panels a, d, and g: Viscosity of set yogurts containing different concentrations of Leuconostoc pseudomesenteroides XG5 (XG5 EPS) at different shear rates [strain $(\gamma)=0.5 \%$ ]. Panels b, e, and h: storage modulus $\left(\mathrm{G}^{\prime}\right.$; solid symbols) and loss modulus ( $\mathrm{G}^{\prime \prime}$; open symbols), and panels c, f, and i: $\tan \delta\left(\mathrm{G}^{\prime \prime} / \mathrm{G}^{\prime}\right)$ of set yogurt under strain sweep (shear rate: $1,000 \mathrm{~s}^{-1} \times 1 \mathrm{~s}, \gamma=0.5 \%$, frequency $=1 \mathrm{~Hz}$ ) during cold storage (panels $\mathrm{a}, \mathrm{b}, \mathrm{c}=\mathrm{d} 1$; panels $\mathrm{d}, \mathrm{e}, \mathrm{f}=\mathrm{d}$ 7; and panels $\mathrm{g}, \mathrm{h}, \mathrm{i}=\mathrm{d} 14$ ). Black squares $=$ control $(0$ added XG5 EPS); green triangles $=$ LXE (0.1\% added XG5 EPS); and red triangles $=$ HXE (0.5\% added XG5 EPS).

stability of set yogurt (Fu et al., 2018). In addition, Zhao et al. (2020) found that curdlan, a glucan, increased the string-like additional structure and porous structure of the set yogurt. This finding suggested that addition of $0.5 \%$ XG5 EPS improved the stability of the set yogurt, consistent with the data in the WHC, texture profile and viscosity. Accordingly, XG5 EPS is a stabilizer for application in set yogurt production.

\section{CONCLUSIONS}

Leuconostoc pseudomesenteroides is a promising producer of dextran. In this study, the yield of XG5 EPS up to $26.02 \mathrm{~g} / \mathrm{L}$ under the conditions of initial $\mathrm{pH} 7.0$, fermentation temperature of $25^{\circ} \mathrm{C}, 100 \mathrm{rpm}$, fermentation time of $36 \mathrm{~h}$, and sucrose concentration of 100 $\mathrm{g} / \mathrm{L}$ at the laboratory level, and the yield of XG5 EPS was further enhanced to $40.07 \mathrm{~g} / \mathrm{L}$ in a $50-\mathrm{L}$ bioreactor by the fed-batch fermentation. Moreover, the addition of $0.5 \%$ XG5 EPS improved the stability of the set yogurt, including the WHC, texture profile, viscosity, and microstructure during cold storage. These results indicate that XG5 EPS exhibited an industrial production prospect, and XG5 EPS could be considered as a potential stabilizer for industrial production of set yogurt. 

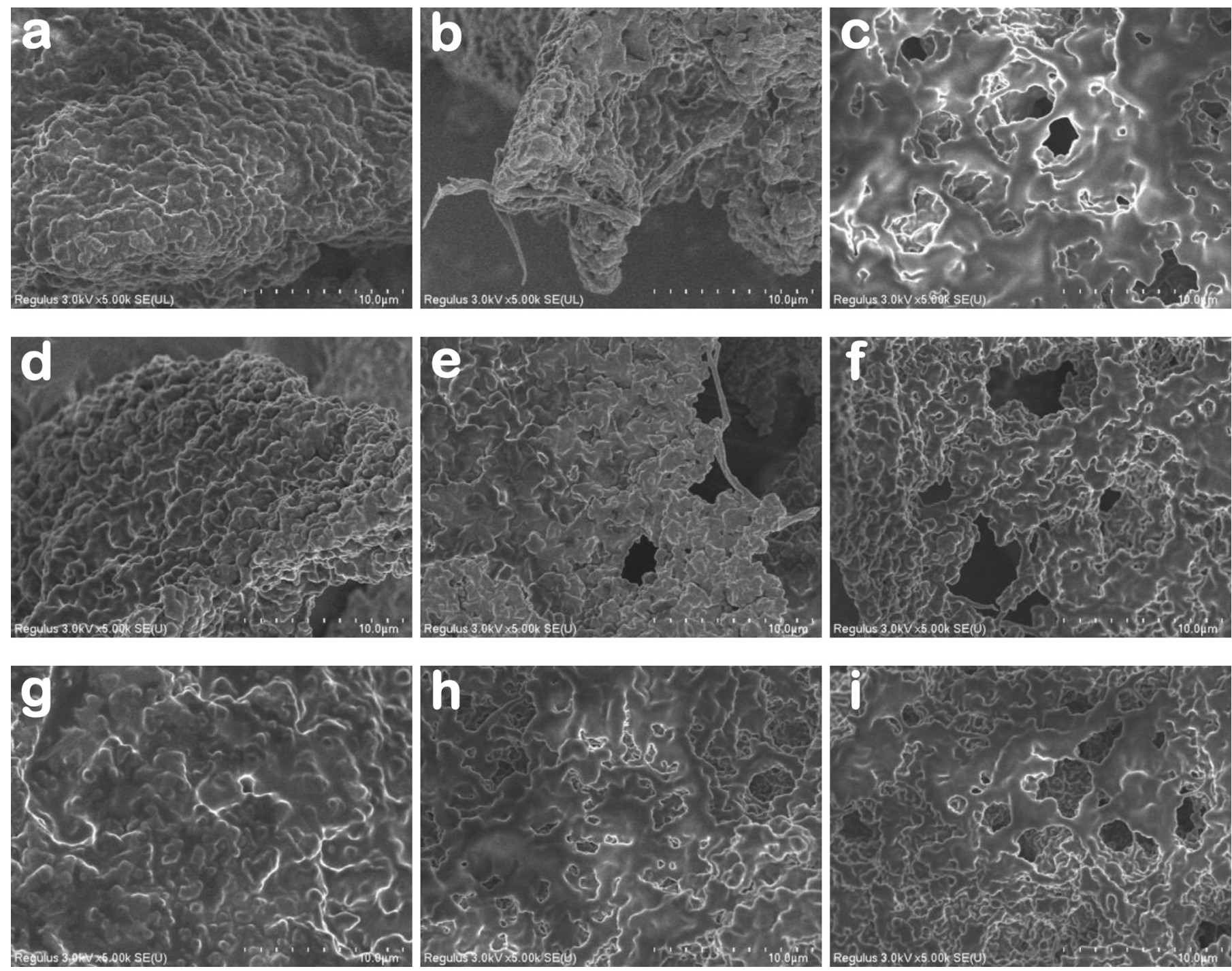

Figure 5. Scanning electron micrographs of set yogurt containing different concentrations of Leuconostoc pseudomesenteroides XG5 exopolysaccharide (XG5 EPS) with magnification of 5,000×. Panels a, d, g: Control (0 added XG5 EPS); panels b, e, h: LXE (0.1\% added XG5 EPS); panels c, f, i: HXE (0.5\% added XG5 EPS) during cold storage (panels a, b, c = d 1; panels d, e, f = d 7; and panels g, h, i = d 14). Scale bar $=10 \mu \mathrm{m}$.

\section{ACKNOWLEDGMENTS}

The authors thank Yusong Cheng (Bioprox, NoyantVillages, France) for donating yogurt starter of set yogurt. This work was supported by the Tianjin Key Research and Development Plan (19YFZCSN00100). The authors have not stated any conflicts of interest.

\section{REFERENCES}

Abdeshahian, P., J. J. Ascencio, R. R. Philippini, F. A. F. Antunes, J. C. Dos Santos, and S. S. da Silva. 2020. Utilization of sugarcane straw for production of beta-glucan biopolymer by Lasiodiplodia theobromae CCT 3966 in batch fermentation process. Bioresour. Technol. 314:123716. https://doi.org/10.1016/j.biortech.2020 .123716 .
Almusallam, I. A., I. A. Mohamed Ahmed, E. E. Babiker, F. Y. AlJuhaimi, A. Saleh, A. A. Qasem, S. Al Maiman, M. A. Osman, K. Ghafoor, H. A. Hajji, and A. S. Al-Shawaker. 2021. Effect of date palm (Phoenix dactylifera L.) spikelets extract on the physicochemical and microbial properties of set-type yogurt during cold storage. Lebensm. Wiss. Technol. 148:111762. https://doi.org/10 .1016/j.lwt.2021.111762.

Aramsangtienchai, P., T. Kongmon, S. Pechroj, and K. Srisook. 2020. Enhanced production and immunomodulatory activity of levan from the acetic acid bacterium, Tanticharoenia sakaeratensis. Int. J. Biol. Macromol. 163:574-581. https://doi.org/10.1016/j .ijbiomac.2020.07.001.

Barcelos, M. C. S., K. A. C. Vespermann, F. M. Pelissari, and G. Molina. 2020. Current status of biotechnological production and applications of microbial exopolysaccharides. Crit. Rev. Food Sci. Nutr. 60:1475-1495. https://doi.org/10.1080/10408398.2019.1575791.

Belsito, P. C., M. V. S. Ferreira, L. P. Cappato, R. N. Cavalcanti, V. A. S. Vidal, T. C. Pimentel, E. A. Esmerino, C. F. Balthazar, R. P. C. Neto, M. I. B. Tavares, P. B. Zacarchenco, M. Q. Freitas, M. 
C. Silva, R. S. L. Raices, G. M. Pastore, M. A. R. Pollonio, and A. G. Cruz. 2017. Manufacture of Requeijão cremoso processed cheese with galactooligosaccharide. Carbohydr. Polym. 174:869 875. https://doi.org/10.1016/j.carbpol.2017.07.021.

Bomfim, V. B., J. H. Pereira Lopes Neto, K. S. Leite, É. de Andrade Vieira, M. Iacomini, C. M. Silva, K. M. Olbrich dos Santos, and H. R. Cardarelli. 2020. Partial characterization and antioxidant activity of exopolysaccharides produced by Lactobacillus plantarum CNPC003. Lebensm. Wiss. Technol. 127:109349. https://doi.org/ $10.1016 / j . l w t .2020 .109349$

Chen, F., G. Huang, and H. Huang. 2020. Preparation and application of dextran and its derivatives as carriers. Int. J. Biol. Macromol. 145:827-834. https://doi.org/10.1016/j.ijbiomac.2019.11.151.

Castro-Rodriguez, D., H. Hernandez-Sanchez, and J. Yanez-Fernandez. 2019. Structural characterization and rheological properties of dextran produced by native strains isolated of Agave salmiana. Food Hydrocoll. 90:1-8. https://doi.org/10.1016/j.foodhyd.2018 .11 .052 .

Dilna, S. V., H. Surya, R. G. Aswathy, K. K. Varsha, D. N. Sakthikumar, A. Pandey, and K. M. Nampoothiri. 2015. Characterization of an exopolysaccharide with potential health-benefit properties from a probiotic Lactobacillus plantarum RJF4. Lebensm. Wiss. Technol. 64:1179-1186. https://doi.org/10.1016/j.lwt.2015.07.040.

Farinazzo, F. S., L. J. Valente, M. B. Almeida, A. S. Simionato, M. T. Carlos Fernandes, C. S. Ishii Mauro, A. A. Bosso Tomal, and S. Garcia. 2020. Characterization and antioxidant activity of an exopolysaccharide produced by Leuconostoc pseudomesenteroides JF17 from juçara fruits (Euterpe edulis Martius). Process Biochem. 91:141-148. https://doi.org/10.1016/j.procbio.2019.12.005.

Fessard, A., and F. Remize. 2019. Genetic and technological characterization of lactic acid bacteria isolated from tropically grown fruits and vegetables. Int. J. Food Microbiol. 301:61-72. https://doi.org/ 10.1016/j.ijfoodmicro.2019.05.003.

Freitas, F., C. A. V. Torres, and M. A. M. Reis. 2017. Engineering aspects of microbial exopolysaccharide production. Bioresour. Technol. 245(Part B):1674-1683. https://doi.org/10.1016/j.biortech 2017.05.092

Fu, R., J. Li, T. Zhang, T. Zhu, R. Cheng, S. Wang, and J. Zhang. 2018. Salecan stabilizes the microstructure and improves the rheological performance of yogurt. Food Hydrocoll. 81:474-480. https: //doi.org/10.1016/j.foodhyd.2018.03.034.

Hovjecki, M., Z. Miloradovic, N. Mirkovic, A. Radulovic, P. Pudja, and J. Miocinovic. 2021. Rheological and textural properties of goat's milk set-type yoghurt as affected by heat treatment, transglutaminase addition and storage. J. Sci. Food Agric. 101:5898-5906. https://doi.org/10.1002/jsfa.11242.

Jia, K., X. Tao, Z. Liu, H. Zhan, W. He, Z. Zhang, Z. Zeng, and H. Wei. 2019. Characterization of novel exopolysaccharide of Enterococcus faecium WEFA23 from infant and demonstration of its in vitro biological properties. Int. J. Biol. Macromol. 128:710-717. https://doi.org/10.1016/j.ijbiomac.2018.12.245.

Kanimozhi, J., I. G. Moorthy, R. Sivashankar, and V. Sivasubramanian. 2017. Optimization of dextran production by Weissella cibaria NITCSK4 using response surface methodology-genetic algorithm based technology. Carbohydr. Polym. 174:103-110. https://doi .org/10.1016/j.carbpol.2017.06.021.

Kaur, R., and C. S. Riar. 2020. Sensory, rheological and chemical characteristics during storage of set type full fat yoghurt fortified with barley $\beta$-glucan. J. Food Sci. Technol. 57:41-51. https://doi.org/ 10.1007/s13197-019-04027-7.

Khubber, S., K. Chaturvedi, N. Thakur, N. Sharma, and S. K. Yadav. 2021. Low-methoxyl pectin stabilizes low-fat set yoghurt and improves their physicochemical properties, rheology, microstructure and sensory liking. Food Hydrocoll. 111:106240. https://doi.org/ 10.1016/j.foodhyd.2020.106240.

Li, B., P. Du, E. E. Smith, S. Wang, Y. Jiao, L. Guo, G. Huo, and F. Liu. 2019. In vitro and in vivo evaluation of an exopolysaccharide produced by Lactobacillus helveticus KLDS1.8701 for the alleviative effect on oxidative stress. Food Funct. 10:1707-1717. https:// doi.org/10.1039/C8FO01920G.
Li, R., C. Zhu, X. Bian, X. Jia, N. Tang, and Y. Cheng. 2020a. An antioxidative galactomannan extracted from Chinese Sesbania cannabina enhances immune activation of macrophage cells. Food Funct. 11:10635-10644. https://doi.org/10.1039/D0FO02131H.

Li, X., X. Wang, X. Meng, L. Dijkhuizen, and W. Liu. 2020b. Structures, physico-chemical properties, production and (potential) applications of sucrose-derived $\alpha$-D-glucans synthesized by glucansucrases. Carbohydr. Polym. 249:116818. https://doi.org/10.1016/j carbpol.2020.116818.

Liu, Y., B. Zhang, S. A. Ibrahim, S. S. Gao, H. Yang, and W. Huang. 2016. Purification, characterization and antioxidant activity of polysaccharides from Flammulina velutipes residue. Carbohydr. Polym. 145:71-77. https://doi.org/10.1016/j.carbpol.2016.03.020.

Lynch, K. M., E. Zannini, A. Coffey, and E. K. Arendt. 2018. Lactic acid bacteria exopolysaccharides in foods and beverages: Isolation, properties, characterization, and health benefits. Annu. Rev. Food Sci. Technol. 9:155-176. https://doi.org/10.1146/annurev-food -030117-012537.

Mummaleti, G., C. Sarma, S. Kalakandan, V. Sivanandham, A. Rawson, and A. Anandharaj. 2021. Optimization and extraction of edible microbial polysaccharide from fresh coconut inflorescence sap: An alternative substrate. Lebensm. Wiss. Technol. 138:110619. https://doi.org/10.1016/j.lwt.2020.110619.

Nguyen, P. T. M., O. Kravchuk, B. Bhandari, and S. Prakash. 2017. Effect of different hydrocolloids on texture, rheology, tribology and sensory perception of texture and mouthfeel of low-fat potset yoghurt. Food Hydrocoll. 72:90-104. https://doi.org/10.1016/ j.foodhyd.2017.05.035.

Pan, L., Y. Han, and Z. Zhou. 2020. In vitro prebiotic activities of exopolysaccharide from Leuconostoc pseudomesenteroides XG5 and its effect on the gut microbiota of mice. J. Funct. Foods 67:103853. https://doi.org/10.1016/j.jff.2020.103853.

Siddiqui, N. N., A. Aman, A. Silipo, S. A. Qader, and A. Molinaro. 2014. Structural analysis and characterization of dextran produced by wild and mutant strains of Leuconostoc mesenteroides. Carbohydr. Polym. 99:331-338. https://doi.org/10.1016/j.carbpol.2013 .08 .004 .

da Silva, D. F., S. B. S. Ferreira, M. L. Bruschi, M. Britten, and P. T. Matumoto-Pintro. 2016. Effect of commercial konjac glucomannan and konjac flours on textural, rheological and microstructural properties of low fat processed cheese. Food Hydrocoll. 60:308-316. https://doi.org/10.1016/j.foodhyd.2016.03.034.

Sun, M., Q. Wang, M. Zhang, G. Zhang, T. Wu, R. Liu, W. Sui, J. Zhang, J. Yin, and M. Zhang. 2020. Leuconostoc pseudomesenteroides improves microbiota dysbiosis and liver metabolism imbalance and ameliorates the correlation between dihydroceramide and strains of Firmicutes and Proteobacteria in high fat diet obese mice. Food Funct. 11:6855-6865. https://doi.org/10.1039/ D0FO01009J.

Tamime, A. Y., and R. K. Robinson. 1999. Yoghurt: Science and Technology. 2nd ed. Woodhead Publishing Limited.

Vuillemin, M., F. Grimaud, M. Claverie, A. Rolland-Sabaté, C. Garnier, P. Lucas, P. Monsan, M. Dols-Lafargue, M. Remaud-Siméon, and C. Moulis. 2018. A dextran with unique rheological properties produced by the dextransucrase from Oenococcus kitaharae DSM 17330. Carbohydr. Polym. 179:10-18. https://doi.org/10.1016/j .carbpol.2017.09.056.

Wang, Y., A. Li, X. Jiang, H. Zhang, K. Mehmood, L. Zhang, J. Jiang, M. Waqas, M. Iqbal, and J. Li. 2018. Probiotic potential of Leuconostoc pseudomesenteroides and Lactobacillus Strains isolated from yaks. Front. Microbiol. 9:2987. https://doi.org/10.3389/ fmicb.2018.02987.

Xing, H., R. Du, F. Zhao, Y. Han, H. Xiao, and Z. Zhou. 2018. Optimization, chain conformation and characterization of exopolysaccharide isolated from Leuconostoc mesenteroides DRP105. Int. J. Biol. Macromol. 112:1208-1216. https://doi.org/10.1016/j.ijbiomac .2018.02.068.

Xu, K., M. Guo, J. Du, and Z. Zhang. 2019. Okra polysaccharide: Effect on the texture and microstructure of set yoghurt as a new natural stabilizer. Int. J. Biol. Macromol. 133:117-126. https://doi .org/10.1016/j.ijbiomac.2019.04.035. 
Xu, Y., L. Pitkanen, N. H. Maina, R. Coda, K. Katina, and M. Tenkanen. 2018. Interactions between fava bean protein and dextrans produced by Leuconostoc pseudomesenteroides DSM 20193 and Weissella cibaria Sj 1b. Carbohydr. Polym. 190:315-323. https:// doi.org/10.1016/j.carbpol.2018.02.082.

Yang, Y., F. Feng, Q. Zhou, F. Zhao, R. Du, Z. Zhou, and Y. Han. 2018. Isolation, purification and characterization of exopolysaccharide produced by Leuconostoc pseudomesenteroides YF32 from soybean paste. Int. J. Biol. Macromol. 114:529-535. https://doi .org/10.1016/j.ijbiomac.2018.03.162.

Yang, Y., Q. Peng, Y. Guo, Y. Han, H. Xiao, and Z. Zhou. 2015. Isolation and characterization of dextran produced by Leuconostoc citreum NM105 from manchurian sauerkraut. Carbohydr. Polym. 133:365-372. https://doi.org/10.1016/j.carbpol.2015.07.061.

Zhang, J., Y. Cao, J. Wang, X. Guo, Y. Zheng, W. Zhao, X. Mei, T. Guo, and Z. Yang. 2016. Physicochemical characteristics and bioactivities of the exopolysaccharide and its sulphated polymer from Streptococcus thermophilus GST-6. Carbohydr. Polym. 146:368 375. https://doi.org/10.1016/j.carbpol.2016.03.063.

Zhang, Z., J. Wang, L. Liu, Q. Shun, W. Shi, X. Liu, and F. Wang. 2019. The optimum conditions and mechanism for increasing exopolysaccharide production of Truffles melanosporum by Dioscorea saponins. Lebensm. Wiss. Technol. 107:331-339. https://doi.org/ 10.1016/j.lwt.2019.03.011

Zhao, Y., R. Fu, and J. Li. 2020. Effects of the $\beta$-glucan, curdlan, on the fermentation performance, microstructure, rheological and textural properties of set yogurt. Lebensm. Wiss. Technol. 128:109449. https://doi.org/10.1016/j.lwt.2020.109449.

Zhou, Q., F. Feng, Y. Yang, F. Zhao, R. Du, Z. Zhou, and Y. Han. 2018. Characterization of a dextran produced by Leuconostoc pseudomesenteroides XG5 from homemade wine. Int. J. Biol. Macromol. 107(Part B):2234-2241. https://doi.org/10.1016/j.ijbiomac .2017.10.098.

Zhou, X., K. Zhang, W. Qi, Y. Zhou, T. Hong, T. Xiong, M. Xie, and S. Nie. 2019. Exopolysaccharides from Lactobacillus plantarum NCU116 enhances colonic mucosal homeostasis by controlling epithelial cell differentiation and c-Jun/Muc2 signaling. J. Agric. Food Chem. 67:9831-9839. https://doi.org/10.1021/acs.jafc .9b03939.

\section{ORCIDS}

Lei Pan ำ https://orcid.org/0000-0002-7420-0991

Qi Wang (으 https://orcid.org/0000-0001-8571-3568

Liangfan Qu • https://orcid.org/0000-0002-5354-8614

Lu Liang (ㄴ) https://orcid.org/0000-0002-9015-2408

Ye Han ( https://orcid.org/0000-0003-3902-0351

Xianghe Wang • https://orcid.org/0000-0002-5279-9286

Zhijiang Zhou @ https://orcid.org/0000-0003-4226-8120 